\title{
Some like it varied: individual differences in preference for feed variety in dairy heifers
}

Article

Accepted Version

Creative Commons: Attribution-Noncommercial-No Derivative Works 4.0

Meagher, R. K., Weary, D. M. and von Keyserlingk, M. A.G. (2017) Some like it varied: individual differences in preference for feed variety in dairy heifers. Applied Animal Behaviour Science, 195 (195). pp. 8-14. ISSN 0168-1591 doi: https://doi.org/10.1016/j.applanim.2017.06.006 Available at https://centaur.reading.ac.uk/70729/

It is advisable to refer to the publisher's version if you intend to cite from the work. See Guidance on citing.

Published version at: https://doi.org/10.1016/j.applanim.2017.06.006

To link to this article DOI: http://dx.doi.org/10.1016/j.applanim.2017.06.006

Publisher: Elsevier

All outputs in CentAUR are protected by Intellectual Property Rights law, including copyright law. Copyright and IPR is retained by the creators or other copyright holders. Terms and conditions for use of this material are defined in the End User Agreement.

www.reading.ac.uk/centaur 
Central Archive at the University of Reading

Reading's research outputs online 
1 Some like it varied: individual differences in preference for feed variety in dairy

2 heifers

3 Rebecca K. Meagher ${ }^{1, a}$, Daniel M. Weary ${ }^{1}$, Marina A.G. von Keyserlingk ${ }^{1}$

$4 \quad{ }^{1}$ Animal Welfare Program, Faculty of Land and Food Systems, University of British

5 Columbia, Vancouver, British Columbia, V6T 1 Z4 Canada

6 a Present address: School of Agriculture, Policy and Development, University of

7 Reading, PO Box 237 Whiteknights, Reading, Berkshire, RG6 6AR UK

9 Corresponding author: Rebecca K. Meagher. E-mail: rkmeagher@gmail.com

12 Abstract

Motivation to explore is believed to be widespread among animals, but

15 exploratory behaviour varies within populations. Offering variety in feed is one simple

16 way of allowing intensively housed dairy cattle to express exploratory foraging

17 behaviour. Individuals' exploration of different feed types, as with other new stimuli,

18 likely reflects a balance between exploratory motivation and fear of novelty. We tested

19 the degree to which Holstein heifers $(n=10)$ preferred variety in feed vs. a constant, high

20 quality mixed ration, by first providing varying types of forages and then varying flavours

21 of mixed feed. We also investigated individual differences in exploratory behaviour by

22 measuring switching between feed bins. Individual consistency in preferences was

23 assessed between tests, and longer-term consistency was evaluated by comparing 
24 these results with behaviour in novel object and novel feed tests before weaning. On

25 average, the heifers preferred the constant, familiar feed (spending on average just $20 \%$

26 of their time at varied feed bins), but this preference varied among individuals (from 0 to

$2746 \%$ of time eating in the forage trial, and 0 to $93 \%$ in the flavour trial). Preference for

28 varied forages correlated positively with intake of novel feed as calves $\left(r_{s}=0.72, n=9\right)$.

29 Preference for varied flavours showed a negative correlation with latency to approach a

30 novel object $\left(r_{s}=-0.65\right)$. It thus appears that preference for variety and exploratory

31 foraging behaviour reflect consistent personality traits. These results suggest that

32 offering novel feeds on a rotating schedule as a supplement to the regular diet may be

33 an effective form of enrichment for at least some individuals within a herd.

34

35 Keywords: foraging behaviour; individual differences; neophobia; curiosity; animal 36 welfare; preference 


\section{Introduction}

39 Animals are often motivated to explore (Berlyne 1960, Hughes 1997, Špinka \&

40 Wemelsfelder 2011). It has been demonstrated, for example, that opportunities to

41 explore can be used as reinforcers for learning tasks (Butler 1953: rhesus macaques;

42 Montgomery 1954: rats), and that rats will sometimes choose to explore new locations

43 over visiting known reward locations (Franks et al. 2013). Motivation to explore is

44 presumed to be common across species because it enables gathering of information

45 about resource availability and proximity of potential threats or mates (see e.g. Inglis et

46 al. 1997). Although the tendency to explore varies between species and taxa, with

47 generalist species hypothesized to be more exploratory (see Glickman \& Sroges 1966,

48 Mench 1998), some exploration when feeding is expected in all species (e.g. moving

49 between locations to try different feed types). Not only is it useful to find higher quality

50 food patches in the wild, but herbivores must consume more than one type of plant to

51 meet dietary requirements (Villalba et al. 2010).

52 Modern dairy farms provide few opportunities to perform feed-related exploratory

53 behaviour; they commonly feed an unvarying diet consisting of a mixture of forage and

54 grains to all animals of a given age or production stage, provided in a constant location.

55 Environments with few and unvarying stimuli may be monotonous for the animals and

56 thus potentially reduce welfare (Wood-Gush \& Vestergaard 1991, Meagher \& Mason

57 2012). Some evidence suggests that variation in feed is preferred to such uniform diets

58 by other ruminants (e.g. Scott \& Provenza 1998). Lambs fed a uniform diet with no

59 opportunity for choice had slower feed intakes than did those allowed to choose

60 between feeds that varied over time, as well as higher cortisol levels and neutrophil to 
61 lymphocyte ratios, suggesting that they might have been experiencing stress (Catanese

62 et al. 2013). Consistent with the hypothesis that cattle prefer variety, all beef heifers

63 tested consumed more than one type of feed when they are offered a choice (Ginane et

64 al. 2002), and calves select different dietary ingredients day to day and at different times

65 of day (Atwood et al. 2001). Cows have approximately 20,000 taste receptors on their

66 tongues, compared to less than 7,000 for humans and 1,700 for dogs (reviewed by

67 Roura et al. 2008), suggesting they may be highly attuned to distinctions in flavour, and

68 perhaps prone to boredom when fed monotonous diets. The first aim of our experiment

69 was therefore to determine whether heifers prefer varied feeds to a nutritionally

70 balanced but unchanging feed.

71 Exploratory behaviour varies within as well as between species. The expression

72 of this behaviour in response to novelty likely reflects a balance of two competing

73 motivations (reviewed by Russell 1973): fear of novelty (neophobia) and motivation to

74 gain information and/or stimulation (i.e. motivation to explore, sometimes called

75 'curiosity'; see e.g. Hughes 1997 and Litman 2005 for discussions of different theories

76 of the motivation underlying exploration). Understanding individual differences in such

77 traits is important because it can influence response to experimental treatments,

78 susceptibility to stress, and perhaps health (see e.g. Carere and Eens 2005; Cavigelli

79 2005). However, little experimental work has been done on this topic in ruminants, and

80 research on feed preferences has typically focused on the group rather than individuals.

81 Our second aim was therefore to determine whether individual differences in preference

82 for varied feed were stable across tests, and the extent to which these differences could

83 be predicted by behaviours associated with fearfulness and curiosity. 


\section{2. Methods}

2.1 Animal housing and care

This research was approved by the University of British Columbia Animal Care

88 Committee (Protocol A15-0117). The subjects were 10 female Holsteins, housed at the

89 University of British Columbia Dairy Education and Research Centre (Agassiz, BC,

90 Canada). These animals were exposed to behavioural tests as calves and as weaned

91 heifers. As calves, animals were housed individually from birth to $48 \pm 3$ days of age, in

92 sawdust-bedded pens $(1.2 \times 2 \mathrm{~m})$. Calves had ad libitum access to water and grain (Hi-

93 Pro Medicated Calf Starter, Chilliwack BC, Canada). For the first $26 \mathrm{~d}$ of life, they were

94 fed $8 \mathrm{~L}$ of milk per day by bottle, split between two feedings. The amount per feeding

95 was then reduced over two days to a total of $4 \mathrm{~L}$ per day. They were then weaned at the

96 time they were moved to a group pen $(48 \pm 3 d)$.

97 As weaned heifers, the animals were housed as a group in a free-stall pen that

98 was deep-bedded with sand, containing 13 lying stalls and 13 headlocks at the feed

99 bunk. All animals had ad libitum access to water. Their regular diet was a total mixed

100 ration (TMR) of corn silage, local fescue and orchardgrass hay, grain, and grass silage

$101(35 \%, 25 \%, 22 \%$, and $19 \%$ of dry matter, respectively; the overall mixture had an

102 average of $44 \%$ dry matter, $17.5 \%$ crude protein, $43 \%$ neutral detergent fibre, and 0.93

$103 \mathrm{Mcal} / \mathrm{kg}$ net energy for gain).

104

1052.2 Feeding behaviour tests 
107 tested when the heifers were aged 41 to 49 weeks old. During the habituation phase,

108 heifers were introduced to the new feeds to be included in the experiment. Timothy and

109 alfalfa hays, a local tall fescue/orchardgrass hay mixture and chopped rye straw were

110 placed in four different bins at the feed bunk simultaneously. Two heifers at a time were

111 provided access for 20 min each for two days, with feed locations rearranged on the

112 second day. Over the next four days, the same procedure was followed but with access

113 to only one forage type per day. The heifers had no access to their regular TMR during

114 these habituation trials. Heifers were paired during this stage to reduce stress

115 associated with isolation and encourage feeding while the test conditions and feeds

116 were novel.

117 In the next phase (i.e. the Forage trial), heifers could choose between a feed bin

118 containing the regular TMR and a bin containing one of these four forage types, with the 119 forage varying day-to-day in a pseudorandom order (each forage being presented an

120 equal number of times once all heifers were eating). Tests were conducted following the 121 protocol of Huzzey et al. (2013), in which heifers were allowed to approach the feed

122 bunk one at a time in daily tests, while the other heifers were held in another section of

123 the pen. The heifers were allowed to enter in the order in which they chose to approach

124 the gate. Tests were 10 min long, and began at the typical feed delivery time

125 (approximately 7:30 a.m.) to ensure that the heifers were motivated to eat. Bins were 126 partially covered by a lid to prevent the animals from seeing the contents before they

127 approached, but were always in the same locations (see Figure 1). Bins were refilled

128 between heifers as needed to maintain equal fill. The heifer's first choice of bin (defined 
129 by the heifer putting her head in the bin and interacting with the feed) and time spent

130 interacting with the feed at each bin were recorded within each trial. Additionally,

131 number of switches between bins was recorded in each trial, reflecting sampling

132 behaviour (cf. Huzzey et al. 2013; Nielsen et al. 1996), which is a form of exploration

133 (see e.g. Eliassen et al. 2007), and latency to feed on the first day of the habituation

134 phase was recorded as a measure of feed neophobia. These tests were continued for

13514 days. The first two days of the Forage trial were excluded from analyses of feed

136 preferences because some heifers were not yet consistently eating; the remaining 12

137 days of data included three presentations of each of the four forage types.

138 The Forage preference test provides a naturalistic treatment, but can be criticized

139 because the different forages also varied nutritionally. Thus, in a second test (the

140 Flavour trial), we used the standard TMR but varied flavour using non-nutritive

141 powdered flavours (Essentials Inc., Abbotsford, BC, Canada) added to this mixed ration.

142 Heifers were habituated to the new flavours and a new feeding location over two days in

143 which they only had access to the flavoured TMR (three flavours on Day 1 and two on

144 Day 2), as in the Forage trial. On the following day, all five flavours were presented

145 simultaneously to assess preferences, with heifers tested one at a time. Preferences

146 were again assessed based on time spent at each bin. Starting the next day, heifers

147 were given the choice among three bins: one containing the regular (unflavoured) TMR,

148 one that varied between four flavours (Power Punch [berry flavoured], Peppermint,

149 Banana and Anise essences), and one with a constant flavour (Caramel Toffee). This

150 third option had been highly consumed in a short pilot trial in which another group of

151 heifers was offered all flavours simultaneously. It was provided to test whether heifers 
152 simply preferred TMR with flavour added rather than variety in flavour per se. This might

153 be expected if, for example, the unflavoured TMR had low palatability.

154 This test was conducted in the alley behind the pen to allow the regular TMR and

155 varied feed to be placed at an equal distance from the entrance to the test area (Figure

156 2). To control for side biases, we placed the varied feed on the left for half the heifers,

157 and on the right for the other half of the heifers. The constant flavour was available on

158 both sides. The same response variables as above were recorded.

159 Health was monitored daily during the testing period following standard farm

160 protocols; no heifers required medication for any illnesses during the trial.

1622.3 Behavioural tests as calves

163 Nine of these calves had been given two tests of neophobia and exploratory

164 motivation as part of an earlier study. A novel object test was conducted at 5 weeks (35

$165 \pm 3 \mathrm{~d}$ ) of age. The object (a ball or plastic basket) was lowered into the pen on a rope.

166 Latency to touch the object and time in contact were recorded over the next $10 \mathrm{~min}$.

167 Although both of these measures are likely affected by both motivational systems in

168 question (e.g. previous work has reported that both are correlated with cortisol and

169 influenced by anxiolytic administration: Van Reenen et al. 2005, 2009), latency is most

170 commonly used in assessing fear (see review by Forkman et al. 2007) and contact

171 duration has been used to measure curiosity or exploration in other species (e.g.

172 Glickman \& Sroges 1966). When heifers were 6.5 weeks ( $45 \pm 3 \mathrm{~d}$ ) of age a food

173 neophobia test was conducted. A bucket containing $3.0 \mathrm{~kg}$ of TMR (as described above)

174 was put on the front of the individual pen in place of the usual grain. Latency to eat was 
175 recorded from video, and the 'as fed' amount consumed in 30 min was calculated by

176 weighing the leftover feed. Predictions for the direction of the relationship expected

177 between these behaviours and those assessed in the following trial are given in Table 1,

178 based on the hypothesis that preference for variety reflects exploratory motivation, and

179 that high latencies to eat when the food is first presented reflects fear of novelty.

180

1812.4 Statistical analyses

182 Preference for variety was assessed within each stage as the proportion of time

183 eating from a varied bin in relation to the total time spent eating, and whether the first

184 bin chosen was varied or stable feed. To test whether varied feed was preferred to

185 normal feed, we calculated the individual means across days within each phase of the

186 study. For the Forage preference trial, a one-sample t-test was used to determine

187 whether the consumption in the last set of tests (the last test for each feed type in the

188 varied bin) differed from zero. This was repeated for the Flavour preference trial, but the

189 data were non-normally distributed according to Shapiro-Wilk tests, and were log-

190 transformed to correct this in further analyses. Due to this non-normality, summary data

191 presented for this trial are medians rather than means. Biases in feeding choices based

192 on feed locations were assessed by calculating binomial probabilities. We also tested

193 whether preferences and levels of exploratory behaviour (switching between feed bins)

194 changed over time within the feeding trials by calculating means for each day across

195 individuals and regressing against test day, since a decrease in exploration might be

196 expected due to decreasing information gain. Changes were considered significant at

197 the $P=0.05$ level. 
To assess whether individual differences in preference for variety reflected

199 lasting differences in fearfulness or exploratory motivation, Spearman rank correlations

200 were calculated between preference in each phase of the study (Forage and Flavour

201 trials) and behaviour in the tests conducted while the subjects were calves. Within the

202 heifer trial, correlations were also calculated between preference for variety in each trial

203 and latency to eat on the first day of the habituation phase (i.e. neophobia), and with

204 switches between bins (exploratory behaviour) in each trial. Correlations were

205 categorized as negligible $(<0.3)$, low $(0.3-0.5)$, moderate $(0.5-0.7)$, high $(0.7-0.9)$ or very

206 high (>0.9) according to Hinkle and colleagues (2003). All analyses were conducted in

207 R (3.2.2, The R Foundation for Statistical Computing).

208

209 3. Results

$210 \quad 3.1$ Group-level feeding preferences

211 The median time spent eating per session in the Forage trial was $456 \mathrm{~s}$ of the

212600 s possible (interquartile range: $355-530$ s). Heifers did not spend more time eating

213 from the varied forage bins than from the familiar TMR; on average, they spent $20 \%$ ( \pm

214 17) of their time feeding from the varied forage bin. The linear regression of proportion

215 of time eating varied forage vs. day showed no change over the 12 days of testing

$216(\mathrm{r}<0.001, P=0.943)$. Similarly, heifers visited the varied bins first in $28 \pm 26 \%$ of the

217 trials. The results were similar for the tests using the flavoured TMR: on average,

218 heifers spent just $6 \%$ (median; interquartile range: $4-16 \%$ ) of their total feeding time at

219 the varied bins, and again this did not vary over the 12 days of testing $(r=0.07$,

$220 P=0.399$ ). Heifers visited these varied bins first in just $12 \%$ (median; interquartile range: 
$2212-17 \%$ ) of trials. In the Flavour trial, heifers spent a median $554 \mathrm{~s}$ eating all foods

222 combined (interquartile range: $517-580 \mathrm{~s}$ ).

223 Heifers showed side preferences in the Flavour trial: on the first day of testing

224 heifers alone, when all flavours were presented simultaneously, nine of ten heifers went

225 to the bins on the left first (binomial probability of this or a more extreme result

226 happening by chance: $P=0.022$ ) and only ate from those bins. This preference

227 continued throughout the trial: a median $89 \%$ (interquartile range: $44-75 \%$ ) of feeding

228 time for the fixed flavour, which was present on both sides, was at the bins to the left of

229 the gate. This side bias was less obvious during the Forage trial, although by the end of

230 this trial heifers tended to go to the bins in the half closer to the entry: all nine chose

231 these bins first on day 12 (vs. 5 of 9 on day $1 ; 62$ of 105 across all heifers and days).

232 The mean number of switches between bins of different feed types did not

233 change over sessions (Forage trial: $r=0.13, P=0.251$; Flavour trial: $r=0.17, P=0.178$ ).

3.2 Individual differences in feeding preferences as heifers

236 Individual differences in preference were observed throughout the study. In the

237 varied Forage trial, individual averages of the proportion of eating time spent at the

238 varied bins ranged from $0 \%$ to $46 \%$. For the Flavour trial, individual differences were

239 influenced by the side bias: the maximum proportion of time eating from the varied bins

240 was only $12 \%$ when it was placed on the right, versus $93 \%$ when on the left (see Figure

2413 3). The preference for variability showed some consistency between the Forage and

242 Flavour preference trials $\left(r_{s}=0.47\right.$; Figure 4). 


\subsection{Relationships within tests}

245 In the calf tests, the two measures taken during the food neophobia tests, latency

246 to eat and amount consumed, were positively correlated $\left(r_{s}=0.63\right)$. There was a low

247 negative correlation between time in contact with the novel object and latency to make

248 contact $\left(n=8, r_{s}=-0.31\right)$.

249 In the heifer trial, preference for varied feed was not predicted by latency to eat

250 on the first day of the habituation phase $\left(r_{s}=0.25\right.$ for Forage trial and 0.26 for Flavour

251 trial). There was, however, a low positive correlation between preference for varied feed

252 and the number of times they switched between bins in the Flavour trial $\left(r_{s}=0.30\right)$, and

253 in the Forage trial $\left(r_{s}=0.48\right)$.

254

255

\subsection{Relationships between tests}

256

In the two tests conducted as calves, neither latency to eat nor intake in the food

258 neophobia test correlated with the latency to touch a novel object $\left(r_{s}=0.23\right.$ and 0.26 ,

259 respectively).

The relationships between the calf novel object test and behaviour in the feeding

261 trial as heifers are summarized in Table 2. For the purpose of these analyses,

262 preference for variety is expressed as proportion of time eating from the variable bins;

263 this measure was very highly correlated with the first choice of bins $\left(r_{s}=0.94\right.$ and 0.91

264 in the Forage and Flavour trials, respectively), so using both was unnecessary. There

265 was a high positive correlation between intake of novel feed as calves and preference

266 for varied feed over TMR in the Forage trial. A moderate correlation was found between 
267 latency to touch a novel object and preference for varied flavour over TMR with no

268 flavour added. Since the side of the alley to which the varied feed was assigned

269 affected preferences, the analyses were split by side. We found a high negative

270 correlation with latency to touch the novel object only when varied flavour was tested on

271 the right; when the varied feed was on the left, there was no relationship. Total time

272 spent in contact with a novel object was moderately correlated with preference for

273 varied feed in the Forage trial.

274 The number of switches between bins, averaged across the Forage and Flavour

275 trials, had a high positive correlation with intake of novel feed as a calf. There was also

276 a moderate correlation between latency to eat the novel forage as a heifer and latency

277 to touch a novel object as a calf; however, this relationship was unexpectedly negative.

278 All remaining correlations were low or negligible.

279

280 4. Discussion

281 On average, heifers did not prefer varied over stable feed, even when there was 282 no energetic or nutritional cost to choosing the varied feed. This finding is surprising 283 given that other work has shown that monotonous flavours are generally less preferred 284 in young animals of another ruminant species, sheep (Scott \& Provenza 1998). This 285 finding also contrasts with results from primates that show a preference for varied over 286 monotonous diets (Addessi et al. 2010). The current results are more in keeping with 287 the common wisdom that farms should aim to keep feed as stable as possible (e.g. 288 Stone 2008). Feeding a consistent diet is thought to improve intake and performance 289 (e.g. milk yield: Sova et al. 2014, but see Yoder et al. 2013 for a counterexample) and is 
290 hypothesized to be better for health (Sova et al. 2014). Cattle and other domestic

291 ruminants tend to be neophobic with regard to food, i.e. they are reluctant to eat novel

292 food items and tend to sample small amounts at first (see e.g. Launchbaugh et al. 1997;

293 Herskin et al. 2003), likely helping them avoid toxic doses (Launchbaugh 1995). If this

294 neophobia was not fully overcome in the time given, it might explain the greater

295 consumption of familiar feed in the current experiment. The heifers may also not have

296 perceived the TMR as uniform or monotonous since it contained many ingredients.

297 Moreover, individual bites may vary slightly in the exact mixture of elements that the

298 heifer ingests, and their many taste buds may make them sensitive to fine distinctions.

299 Still, most heifers consumed at least some varied feed throughout the Forage trial

300 despite the varied feed having lower average energy and protein content (the two major

301 nutritional needs expected to guide choice; see e.g. Bailey, 1995; Villalba et al. 2015)

302 lower than that of the TMR.

303 There are several reasons why feeding behaviour might not always maximize

304 energy gain (cf. Newman et al. 1992). Optimal foraging theory allows for sampling of

305 different feeds to obtain information about feed quality, and predicts this sampling to be

306 more persistent in changing environments, where past experience is a less effective

307 predictor of current conditions (Stephens \& Krebs 1986; Shettleworth 1988). However,

308 in the Flavour trial, all foods offered were consistently of identical high quality and

309 therefore little sampling would be expected (Huzzey et al. 2013). If consumption of

310 varied feed was primarily a form of sampling to gain information about patch quality, we

311 might have expected this to decrease over time as the heifers learned about the feeds.

312 If consumption of the varied feed was limited primarily by feed neophobia rather than 
313 feed value, by contrast, it would have been expected to increase over time. Instead, we

314 found that consumption of the varied feed did not change over time, suggesting that the

315 results reflect a relatively stable preference for some variety in the diet. While the

316 literature on feed preferences often describes 'partial preferences' for consumption of

317 more than one feed as opposed to always choosing a single feed (e.g. McNamara \&

318 Houston 1987, Rutter 2010), there is little discussion of how much needs to be

319 consumed for this to qualify as being partially preferred.

320 Such partial preferences may allow animals to select a more balanced diet

321 (Newman et al. 1992), and choice based on specific nutrients other than energy and

322 protein cannot be absolutely ruled out in the Forage trial here. However, partial

323 preferences can also be seen when there is no evidence of relevant nutritional

324 differences (Newman et al. 1992, Parsons et al. 1994). Preferring feeds that have not

325 been recently consumed, as seen in other ruminants (Parsons et al. 1994, Scott \&

326 Provenza 1998; similar phenomena also being reported in other taxa, e.g. Tuttle et al.

327 1990), may be explained mechanistically by sensory-specific satiety. This is a

328 phenomenon observed in humans, in which foods become subjectively less pleasant as

329 they are consumed, before any physiological consequences of the nutrients can be

330 processed (Rolls 1986). The functional basis for this phenomenon remains unclear, but

331 likely relates to a more general need for sensory change, which has been suggested as

332 one reason for what is called "intrinsic exploration" (Hughes 1997): exploration that

333 appears to be performed for its own sake. This means that opportunities to explore

334 different feeds would be rewarding for individuals with strong exploratory motivation 
335 regardless of the nutritional value of those offerings, and the motivation may be possible

336 to meet with non-feed-related stimuli as well.

337 Although the average consumption of varied feed in both the Forage and Flavour

338 trials was low relative to consumption of regular feed, there was large variation in

339 preference among individuals. While the correlation in preference between the Forage

340 and Flavour trials was low, greater individual consistency may have been seen if not for

341 the side bias in the Flavour trial. Moreover, preferences in these trials were correlated

342 with certain behaviours earlier in life, suggesting some consistent individual traits. The

343 directions of many of these correlations were predicted by the hypothesis that

344 preference for variety reflects exploratory motivation, fear of novelty, or both. Calves

345 that spent more time exploring a novel object at 5 weeks of age were more interested in

346 varied feed as heifers ( 41 weeks and older; Forage trial), and those that ate more novel

347 feed as calves also performed more exploratory behaviour (feed switching) as heifers.

348 Correlations between the calf tests and behaviour in the Flavour trial were weaker,

349 again likely due to the side bias.

$350 \quad$ Novel object latency was a strong predictor of preference in the Flavour trial, with

351 shorter latencies being associated with greater proportional consumption of varied feed,

352 especially when controlling for the side of the alley to which the feeds were assigned.

353 These results are similar to the finding that lambs which show fewer signs of distress in

354 a novel setting consume more of a novel feed (Villalba et al. 2009). In the current

355 experiment, the correlations between latency to eat novel feed during habituation in the

356 heifer trials and behaviour in the calf tests were largely weak and were in the opposite

357 direction to that predicted. The reasons for this need further investigation, but novel feed 
358 latency could reflect a different type of exploration than sampling does, with strategies

359 of exploration differing between individuals (as in birds: Van Overveld \& Matthysen

360 2013). Regardless, the correlations found suggest that preference for varied feed is

361 related to stable personality traits (defined as individual characteristics describing

362 stability of behaviour over time; see Gosling [2008] for discussion of the term).

363 Progress in understanding personality traits and their significance in cattle is

364 hindered by the lack of reliable, validated measures for the species (see e.g. Meagher

365 et al. 2016; Mackay 2013). To be considered a true measure of personality, an indicator

366 must be repeatable, yet data on repeatability is often limited (see e.g. Svartberg et al.

367 2005). There has been criticism of some of the common types of test used in animals,

368 because they are done in artificial and potentially stress-inducing settings and might not

369 accurately reflect natural behaviour (Carter et al. 2013; Biro 2013). The types of feeding

370 test used here, by contrast, were relatively naturalistic. If these types of test prove to be

371 valid indicators of motivation to explore and neophobia in cattle, they may prove useful

372 for research as they are quick and easy to conduct, and can be done in the home pen.

373 These tests also seem to be relatively straightforward to interpret since the animals are

374 making an active choice between novel or varied feed and routine feeds, whereas

375 measures such as latency to approach an object are influenced by various competing

376 motivations (e.g. motivation to lie down) which can be difficult to disentangle.

377 We suggest that offering rarely experienced feeds may provide welfare benefits

378 for at least some individuals by allowing them to express exploratory behaviour. Varied

379 feeds might also function as a reinforcer in training cattle to perform desired behaviours

380 such as entering a robotic milking machine. This use would avoid some of the difficulties 
381 with using varied feed as enrichment in the home pen, such as increased competition,

382 with dominant animals monopolizing access to preferred feeds in group-fed animals

383 (see Mandel et al. 2016). Offering opportunities for choice may also have psychological

384 benefits even if little of the less preferred feed is chosen; this may also be true of

385 choices unrelated to food. Monkeys, for example, "choose to choose": they prefer to

386 control the order of tasks themselves rather than having this assigned, all else being

387 equal (Perdue et al. 2014). The correlations between choice of varied feed and

388 exploratory behaviour as calves support the conclusion that both relate to a broader

389 exploratory motivation, rather than something specific to the feed such as flavour

390 boredom or motivation for a specific highly palatable food amongst the options, and any

391 opportunities for choice and exploration might improve welfare.

392 It has also been suggested that allowing individuals to choose their own diets is

393 valuable because physiological needs differ across individuals (Atwood et al. 2001,

394 Manteca et al. 2008). This assumes that animals have some level of 'nutritional

395 wisdom' and are able to select feeds based on the nutrients they require; there is some

396 evidence to support this view (Manteca et al. 2008). The importance of personalized

397 diets taking into account individual differences in needs is increasingly recognized in

398 human nutrition (e.g. Noecker \& Borenstein 2015), and ways of identifying those needs

399 are currently being studied (e.g. by assessing glycemic responses to meals: Zeevi et al.

400 2015). Aside from the direct physiological effects of giving animals variety or choice in

401 their diets, there is some evidence that monotonous prescribed diets can cause stress

402 (Catanese et al. 2013) and, in early life, even influence later stress responsiveness 
403 (Villalba et al 2012). These effects may result from the animals being unable to act upon 404 their 'wisdom'.

405 There were a few limitations to the current experiment. The side bias may reflect 406 behavioural lateralization, since cows, like most mammals, do exhibit some laterality, 407 including in their responses to novelty (Robins \& Phillips 2010). However, the bias here 408 emerged over time, not being evident during the initial preference tests when all flavours 409 were presented simultaneously, as one might have expected if there was an innate side 410 preference. The bias may be because the preferred bins to the left of the gate were in 411 front of the home pen and therefore closer to their social group, while the others were in 412 front of a neighbouring pen. This preference for being near the home pen may have

413 become stronger over time as social bonds and familiarity with that pen increased.

414 Whatever the reason, this bias complicated the interpretation of the results. Randomly

415 assigning half of the group to each side allowed detection of this problem, but the 416 strength of the side preference was such that it interfered with our investigation of 417 individual differences. Side biases must be taken into consideration when designing 418 similar experiments in future. The effect of timescale should also be considered; this 419 experiment investigated preferences only in short-term tests over a period of 12 days 420 per trial. Preferences might change over time as the degree of novelty of the feed 421 changes (see e.g. Parsons et al. 1994). Testing for only a short period of the day may 422 also result in individuals being ranked differently than they would be in tests of longer 423 duration (Dumont et al. 1995), although this may be less of a concern in this context 424 than when investigating feeding on pastures where factors such as sward height 425 change over time. Finally, replication of this work is needed to confirm the relationships 
426 between feeding preferences and relevant personality traits, and to more clearly

427 distinguish between fear and curiosity or desire for stimulation as underlying

428 motivations.

$429 \quad$ Future research should also investigate how the early rearing environment

430 influences preference for variety. These heifers had been individually reared in indoor

431 pens, and as such were expected to be less flexible and more afraid of novelty,

432 including novel feeds, than they would be if they had been housed socially and in more

433 complex environments (see Meagher et al. 2015; Costa et al. 2015). The animals had

434 also not been provided much experience with diversity of feed, except in the form of the

435 brief food neophobia tests described. In lambs, early experience with varied diets

436 increases willingness to eat novel feeds or flavours (e.g. Catanese et al. 2012). Average

437 preferences might thus differ in other management systems.

438 In summary, many of the heifers tested choose to consume standard TMR rather

439 than novel or varied feed, but most individuals exhibited some exploratory feeding

440 behaviour. The range in time devoted to investigating and consuming feed from varied

441 bins, even when there was some energetic cost to this behaviour, suggests that at least

442 some individuals are motivated to obtain variety in their feed. Some individual

443 consistency in animals' responses to novelty across time can be expected based on the

444 relationship between their feeding choices and their behaviour during the milk-feeding

445 period. Offering a choice of feed at least for some portion of the day might improve

446 welfare, particularly on farms or in pens in which the animals show high levels of

447 exploration. Responses to changing feeds may also provide a simple, naturalistic

448 measure of exploratory tendencies for use in future research. 


\section{Acknowledgements}

We thank the staff and students at the UBC Dairy Education and Research

452 Centre, especially Nolan Chalifoux and Thomas Ede, Tiffany Tse, Erica Helgeson and

453 Marta Leal for their assistance with data collection. Thank you also to Essentials Inc. for

454 providing the flavours added to the feed and advising on which flavours might be

455 preferred. Funding for the study was provided by a Universities Federation for Animal

456 Welfare (UFAW) Small Project Grant to RKM. Additional support was provided through

457 a NSERC Discovery grant to MvK.

\section{References}

Addessi, E., Mancini, A., Crescimbene, L., Ariely, D., Visalberghi, E., 2010. How to spend a token? Trade-offs between food variety and food preference in tufted capuchin monkeys (Cebus apella). Behav. Processes 83, 267-275.

Atwood, S.B., Provenza, F.D., Wiedmeier, R.D., Banner, R.E., 2001. Influence of freechoice vs mixed-ration diets on food intake and performance of fattening calves. J. Anim. Sci. 79, 3034-3040.

Bailey, D.W., 1995. Daily selection of feeding areas by cattle in homogeneous and heterogeneous environments. Appl. Anim. Behav. Sci. 45, 183-200.

472 Berlyne, D.E., 1960. Conflict, Arousal, and Curiosity. McGraw-Hill, New York.

473 Biro, P.A., 2013. On the use of rapid assays in personality research: a response to 474 Edwards et al. Anim. Behav. 86, e1-e3.

475 Butler, R.A., 1953. Discrimination Learning by Rhesus Monkeys to Visual-Exploration 476 Motivation. J. Comp. Physiol. Psychol. 46, 95-98. 
477 Carere, C., Eens, M., 2005. Unravelling Animal Personalities: How and Why Individuals 478 Consistently Differ. Behaviour 142, 1149-1157.

479 Carter, A.J., Feeney, W.E., Marshall, H.H., Cowlishaw, G., Heinsohn, R., 2013. Animal 480 personality: what are behavioural ecologists measuring? Biological Reviews 88, 465481475.

482 Catanese, F., Distel, R.A., Provenza, F.D., Villalba, J.J., 2012. Early experience with 483 diverse foods increases intake of nonfamiliar flavors and feeds in sheep. J. Anim. Sci. $48490,2763-2773$.

485 Catanese, F., Obelar, M., Villalba, J.J., Distel, R.A., 2013. The importance of diet choice 486 on stress-related responses by lambs. Appl. Anim. Behav. Sci. 148, 37-45.

487 Cavigelli, S.A., 2005. Animal personality and health. Behaviour 142, 1223-1244.

488 Costa, J.H.C., Meagher, R.K., von Keyserlingk, M.A.G., Weary, D.M., 2015. Early pair 489 housing increases solid feed intake and weight gains in dairy calves. J. Dairy Sci. 98, $490 \quad 6381-6386$.

491 Dumont, B., D'hour, P., Petit, M., 1995. The usefulness of grazing tests for studying the ability of sheep and cattle to exploit reproductive patches of pastures. Appl. Anim. Behav. Sci. 45, 79-88.

494 Eliassen, S., Jørgensen, C., Mangel, M., Giske, J., 2007. Exploration or Exploitation: Life Expectancy Changes the Value of Learning in Foraging Strategies. Oikos 116, 513-523.

497 Forkman, B., Boissy, A., Meunier-Salauen, M.C., Canali, E., Jones, R.B., 2007. A 498 critical review of fear tests used on cattle, pigs, sheep, poultry and horses. Physiol. 499 Behav. 92, 340-374.

500 Franks, B., Champagne, F.A., Higgins, E.T., 2013. How Enrichment Affects Exploration 501 Trade-Offs in Rats: Implications for Welfare and Well-Being. PLoS One 8, e83578.

502 Ginane, C., Baumont, R., Lassalas, J., Petit, M., 2002. Feeding behaviour and intake of 503 heifers fed on hays of various quality, offered alone or in a choice situation. Anim. Res. 504 51, 177-188.

505 Glickman, S.E., Sroges, R.W., 1966. Curiosity in zoo animals. Behaviour 26, 151-188.

506 Gosling, S.D., 2008. Personality in non-human animals. Social and Personality 507 Psychology Compass 2, 985-1001.

508 Hedlund, L., Løvlie, H., 2015. Personality and production: Nervous cows produce less 509 milk. J. Dairy Sci. 98, 5819-5828. 
510 Herskin, M.S., Munksgaard, L., Kristensen, A., 2003. Behavioural and adrenocortical 511 responses of dairy cows toward novel food: effects of food deprivation, milking

512 frequency and energy density in the daily ration. Appl. Anim. Behav. Sci. 82, 251-265.

513 Hinkle, D.E., Wiersma, W., Jurs, S.G., 2003. Applied Statistics for the Behavioral 514 Sciences, 5th Ed. ed. Houghton Mifflin, Boston, USA.

515

516

517

518

519

520

521

522

523

524

525

526

527

528

529

530

531

532

533

534

535

536

537

538

539

540

541

542

Hughes, R.N., 1997. Intrinsic exploration in animals: motives and measurement. Behav. Processes 41, 213-226.

Huzzey, J.M., Fregonesi, J.A., von Keyserlingk, M.A.G., Weary, D.M., 2013. Sampling behavior of dairy cattle: Effects of variation in dietary energy density on behavior at the feed bunk. J. Dairy Sci. 96, 247-256.

Inglis, I.R., Forkman, B., Lazarus, J., 1997. Free food or earned food? A review and fuzzy model of contrafreeloading. Anim. Behav. 53, 1171-1191.

Launchbaugh, K., 1995. Effects of neophobia and aversions on feed intake: why feedlot cattle sometimes refuse to eat nutritious feeds. Intake by Feedlot Cattle: Symposium Proceedings P-942, 36-48.

Launchbaugh, K.L., Provenza, F.D., Werkmeister, M.J., 1997. Overcoming food neophobia in domestic ruminants through addition of a familiar flavor and repeated exposure to novel foods. Appl. Anim. Behav. Sci. 54, 327-334.

Litman, J.A., 2005. Curiosity and the pleasures of learning: Wanting and liking new information. Cognition \& Emotion 19, 793-814.

MacKay, J.R.D., 2013. Characterising personality traits in cattle using biotelemetry systems.

Mandel, R., Whay, H.R., Klement, E., Nicol, C.J., 2016. Invited review: Environmental enrichment of dairy cows and calves in indoor housing. J. Dairy Sci. 99, 1695-1715.

Manteca, X., Villalba, J.J., Atwood, S.B., Dziba, L., Provenza, F.D., 2008. Is dietary choice important to animal welfare? J Vet Behav 3, 229-239.

McNamara, J.M., Houston, A.I., 1987. Partial preferences and foraging. Anim. Behav. 35, 1084-1099.

Meagher, R.K., Mason, G.J., 2012. Environmental Enrichment Reduces Signs of Boredom in Caged Mink. Plos One 7, e49180.

Meagher, R.K., Daros, R.R., Costa, J.H.C., von Keyserlingk, M.A.G., Hötzel, M.J., Weary, D.M., 2015. Effects of Degree and Timing of Social Housing on Reversal Learning and Response to Novel Objects in Dairy Calves. PLoS ONE 10, e0132828. 
543 Meagher, R.K., von Keyserlingk, M.A.G., Hötzel, M.J., Weary, D.M., 2016.

544 Inconsistency in dairy calves' responses to tests of fearfulness. Appl Anim Behav Sci

$545185,15-22$.

Mench, J.A., 1998. Environmental enrichment and the importance of exploratory behavior, in: Shepherdson, D.J., Mellen, J.D., Hutchins, M. (Eds.). Smithsonian

548 Institution, Washington, DC, USA, pp. 30-46.

Montgomery, K.C., 1954. The role of the exploratory drive in learning. J. Comp. Physiol. Psychol. 47, 60-64.

Nielsen, B.L., Lawrence, A.B., Whittemore, C.T., 1996. Feeding behaviour of growing pigs using single or multi-space feeders. Applied Animal Behaviour Science 47, 235-

553246.

\section{4}

Newman, J.A., Parsons, A.J., Harvey, A., 1992. Not all sheep prefer clover: diet selection revisited. J Ag Sci Camb 119, 275-283.

Noecker, C., Borenstein, E., 2016. Getting Personal About Nutrition. Trends Mol. Med. 22, 83-85.

Parsons, A.J., Newman, J.A., Penning, P.D., Harvey, A., Orr, R.J., 1994. Diet Preference of Sheep: Effects of Recent Diet, Physiological State and Species Abundance. J. Anim. Ecol. 63, 465-478.

Perdue, B., Evans, T., Washburn, D., Rumbaugh, D., Beran, M., 2014. Do monkeys choose to choose? Learning \& Behavior 42, 164-175.

Rauw, W.M., Kanis, E., Noordhuizen-Stassen, E.N., Grommers, F.J., 1998. Undesirable side effects of selection for high production efficiency in farm animals: a review. Livest. Prod. Sci. 56, 15-33.

Robins, A., Phillips, C., 2010. Lateralised visual processing in domestic cattle herds responding to novel and familiar stimuli. Laterality 15, 514-534.

Rolls, B.J., 1986. Sensory-specific Satiety. Nutr. Rev. 44, 93-101.

Roura, E., Humphrey, B., Tedo, G., Ipharraguerre, I., 2008. Unfolding the codes of short-term feed appetence in farm and companion animals. A comparative oronasal nutrient sensing biology review. Canadian Journal of Animal Science 88, 535-558.

Russell, P.A., 1973. Relationships between exploratory behaviour and fear: a review. British Journal of Psychology 63, 417-433. 
574 Rutter, S.M., 2010. Review: Grazing preferences in sheep and cattle: Implications for 575 production, the environment and animal welfare. Canadian Journal of Animal Science $57690,285-293$.

577 Scott, L.L., Provenza, F.D., 1998. Variety of foods and flavors affects selection of 578 foraging location by sheep. Appl. Anim. Behav. Sci. 61, 113-122.

Shettleworth, S.J., Krebs, J.R., Stephens, D.W., Gibbon, J., 1988. Tracking a fluctuating 580 environment: a study of sampling. Anim. Behav. 36, 87-105.

Sova, A.D., LeBlanc, S.J., McBride, B.W., DeVries, T.J., 2014. Accuracy and precision of total mixed rations fed on commercial dairy farms. J. Dairy Sci. 97, 562-571.

Špinka, M., Wemelsfelder, F., 2011. Environmental challenge and animal agency, in: Appleby, M.C., Mench, J.A., Olsson, I.A.S., Hughes, B.O. (Eds.). CAB International, 585 Wallingford, UK, pp. 27-44.

Stephens, D.W., Krebs, J.R., 1986. Foraging Theory. Princeton University Press, 587 Princeton, NJ, USA.

Stone, B., 2008. Considerations in feed bunk management. Tri-State Dairy Nutrition Conference Proceedings , 113-123.

590 Svartberg, K., 2005. Consistency of personality traits in dogs. Animal behaviour 69, $591283-291$.

van Overveld, T., Matthysen, E., 2013. Personality and Information Gathering in Free593 Ranging Great Tits. PLoS ONE 8, 1-9.

594 Van Reenen, C.G., O'Connell, N.E., Van der Werf, J.T.N., Korte, S.M., Hopster, H., 595 Jones, R.B., Blokhuis, H.J., 2005. Responses of calves to acute stress: Individual 596 consistency and relations between behavioral and physiological measures. Physiol. 597 Behav. 85, 557-570.

598 Van Reenen, C.G., Hopster, H., Van der Werf, J.T.N., Engel, B., Buist, W.G., Jones, 599 R.B., Blokhuis, H.J., Korte, S.M., 2009. The benzodiazepine brotizolam reduces fear in 600 calves exposed to a novel object test. Physiol. Behav. 96, 307-314.

601 Villalba, J.J., Manteca, X., Provenza, F.D., 2009. Relationship between reluctance to 602 eat novel foods and open-field behavior in sheep. Physiol. Behav. 96, 276-281.

603 Villalba, J.J., Provenza, F.D., Manteca, X., 2010. Links between ruminants' food 604 preference and their welfare. Animal 4, 1240-1247. 
605 Villalba, J.J., Catanese, F., Provenza, F.D., Distel, R.A., 2012. Relationships between 606 early experience to dietary diversity, acceptance of novel flavors, and open field

607 behavior in sheep. Physiol. Behav. 105, 181-187.

608 Villalba, J.J., Provenza, F.D., Catanese, F., Distel, R.A., 2015. Understanding and 609 manipulating diet choice in grazing animals. Animal Production Science 55, 261-271.

610 Wood-Gush, D.G.M., Vestergaard, K., 1989. Exploratory behavior and the welfare of 611 intensively kept animals. Journal of Agricultural and Environmental Ethics 2, 161-169.

612 Yoder, P.S., St-Pierre, N.R., Daniels, K.M., O'Diam, K.M., Weiss, W.P., 2013. Effects of 613 short-term variation in forage quality and forage to concentrate ratio on lactating dairy 614 cows. J. Dairy Sci. 96, 6596-6609.

615 Zeevi, D., Korem, T., Zmora, N., Israeli, D., Rothschild, D., Weinberger, A., Ben-Yacov, 616 O., Lador, D., Avnit-Sagi, T., Lotan-Pompan, M., Suez, J., Mahdi, J., Matot, E., Malka, 617 G., Kosower, N., Rein, M., Zilberman-Schapira, G., Dohnalová, L., Pevsner-Fischer, 618 M., Bikovsky, R., Halpern, Z., Elinav, E., Segal, E., 2015. Personalized Nutrition by 619 Prediction of Glycemic Responses. Cell 163, 1079-1094. 
621 Table 1. Predicted direction of correlations between measures of response to novelty as

622 calves and behaviour when offered choice of varied (forage type or flavours) or stable

623 feed as weaned heifers.

\begin{tabular}{lllll}
\hline \multicolumn{1}{c}{ Calf } & Novel object & Novel object & Novel feed & Novel feed \\
& latency & contact & latency & intake \\
Heifer & & duration & & \\
\hline Proportion of eating & Negative & Positive & Negative & Positive \\
time spent at varied & & & & \\
bin, Forage trial & & & & \\
\hline Proportion of eating & Negative & Positive & Negative & Positive \\
time spent at varied & & & & \\
bin, Flavour trial & & & & \\
\hline Latency to eat novel & Positive & Negative & Positive & Negative \\
feed (habituation & & & & \\
phase) & & & & \\
\hline \# of switches between & Negative & Positive & Negative & \\
bins (average) & & & & \\
\hline
\end{tabular}


626 Table 2. Spearman correlation coefficients for relationships between heifers' behaviour

627 in neophobia tests as calves and their behaviour when offered choices between varied

628 or stable feed as weaned heifers. $n=8$ for contact durations, $n=9$ for all other values.

629

\begin{tabular}{|c|c|c|c|c|}
\hline Heifer & $\begin{array}{l}\text { Novel object } \\
\text { latency }\end{array}$ & $\begin{array}{l}\text { Novel object } \\
\text { contact } \\
\text { duration }\end{array}$ & $\begin{array}{l}\text { Novel feed } \\
\text { latency }\end{array}$ & $\begin{array}{l}\text { Novel feed } \\
\text { intake }\end{array}$ \\
\hline $\begin{array}{l}\text { Proportion of eating } \\
\text { time spent at varied bin, } \\
\text { Forage trial }\end{array}$ & -0.26 & 0.54 & -0.39 & 0.72 \\
\hline $\begin{array}{l}\text { Proportion of eating } \\
\text { time spent at varied bin, } \\
\text { Flavour trial }\end{array}$ & $\begin{array}{l}-0.65 \\
-1 \text { among those } \\
\text { with TMR on the } \\
\text { left side }\end{array}$ & 0.29 & -0.29 & $-0.24^{1}$ \\
\hline $\begin{array}{l}\text { Latency to eat novel } \\
\text { feed (habituation phase } \\
\text { before Forage trial) }\end{array}$ & $-0.60^{1}$ & $0.24^{1}$ & $-0.48^{1}$ & $0.44^{1}$ \\
\hline $\begin{array}{l}\text { \# of switches between } \\
\text { bins (average) }\end{array}$ & -0.08 & 0.42 & -0.55 & 0.71 \\
\hline
\end{tabular}

630 Bold text indicates high correlation, italics indicate moderate, according to Hinkle et al.

631 (2003).

$632{ }^{1}$ Values are in the opposite direction of the prediction

633

634 
638 Figure 1. Pen layout for varied forage preference trial. VAR $=$ bins containing a forage

639 that varied day-to-day; TMR = bins containing regular total mixed ration.

641 Figure 2 Pen layout for varied flavour preference trial. For half of the heifers, the 642 positions of the plain (unflavoured TMR) and varied (TMR with one of four flavours 643 added each day) bins were reversed. Fixed flavour bins had the same flavour added 644 each day.

645

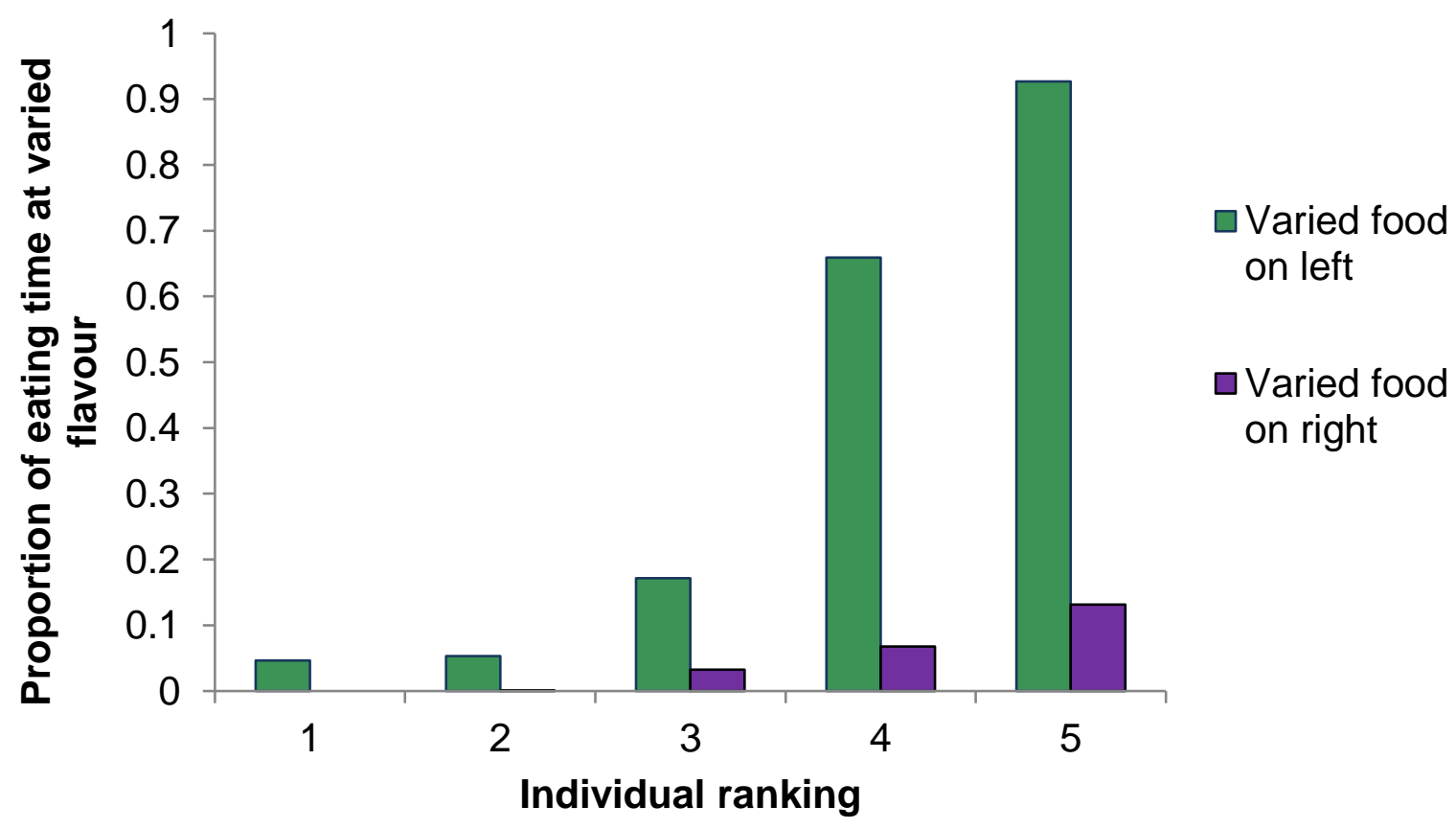

647 Figure 3 Individual differences in the proportion of all time eating heifers spent eating 648 TMR from bins where the flavour varied, split by the side of the alley in which this bin 
649 was placed. High numbers on the $\mathrm{x}$-axis indicate higher proportions of varied feed

650 consumed relative to other heifers. $n=5$ per side.

651

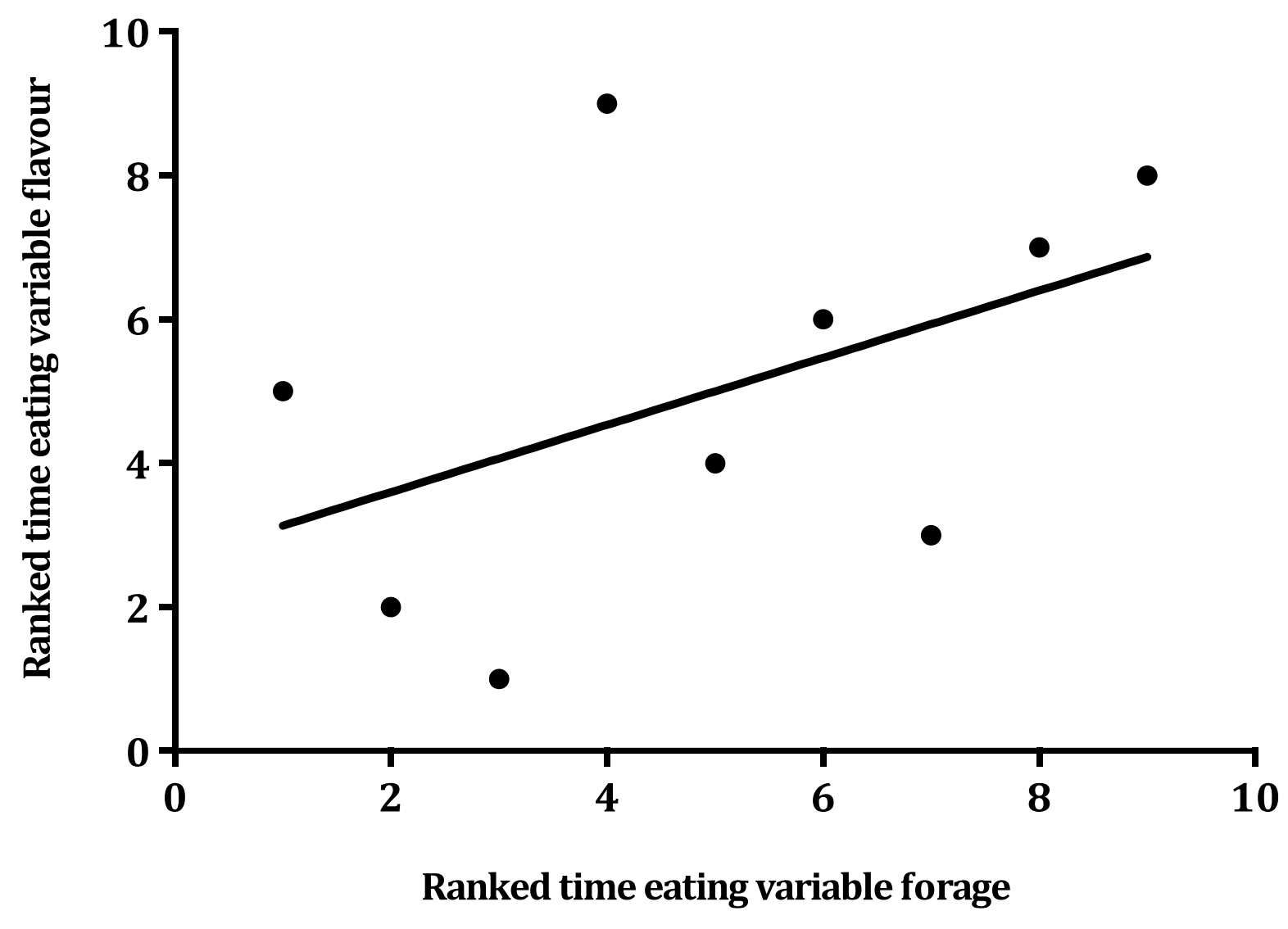

Figure 4 Consistency in proportion of eating time individual heifers spent at the varied

654 bin when the feed was varied forage vs. TMR of varied flavours. $n=9$. 